\title{
Segmentasi Kondisi Psikografis Masyarakat Berdasarkan Konsep VALS (Value and Lifestyle) di Kelurahan Kedung Cowek
}

\author{
Gita Toruli Sidauruk dan Putu Gde Ariastita \\ Perencanaan Wilayah dan Kota, Fakultas Arsitektur Desain dan Perencanaan \\ Institut Teknologi Sepuluh Nopember (ITS) \\ e-mail: ariastita@urplan.its.ac.id
}

\begin{abstract}
Abstrak-Kelurahan Kedung Cowek merupakan salah satu prioritas pertama penanganan kumuh di Kota Surabaya. Namun, program penanganan kekumuhan yang selama ini sudah dilakukan seringkali mengalami kegagalan. Hal ini disebabkan oleh partisipasi masyarakat setempat untuk terlibat dalam program perbaikan permukiman masih tergolong rendah. Dalam upaya penanganan kumuh tersebut, pemerintah harus memberikan program yang sesuai dengan kondisi masyarakat terkait kecenderungannya untuk terlibat dalam suatu program. Pada hakikatnya, kondisi psikografis dapat menggambarkan sikap dan tanggapan seseorang terhadap suatu program pembangunan secara mendalam dibandingkan dengan kondisi demografisnya. Oleh karena itu, dengan berlokasi di RW 2 dan 3 Kelurahan Kedung Cowek, penelitian ini bertujuan untuk mensegmentasikan kondisi psikografis masyarakat ke dalam 8 variabel psikografis menurut konsep VALS (Value and Lifestyle), yaitu segmen innovators, thinkers, believers, achievers, strivers, experiencers, makers dan survivors. Proses ini dilakukan dengan metode scoring menggunakan skala likert secara kuantitatif. Output dari penelitian ini adalah teridentifikasinya kondisi psikografis masyarakat di Kelurahan Kedung Cowek yang beragam. Kondisi psikografis terbanyak adalah believers, sementara yang paling sedikit adalah makers.
\end{abstract}

Kata Kunci- Partisipasi Masyarakat, Penanganan Kumuh, Segmentasi Psikografis.

\section{PENDAHULUAN}

$\mathrm{U}$ PAYA mengatasi permasalahan permukiman kumuh merupakan isu utama dalam pembangunan perkotaan di Indonesia. Hal ini dikarenakan penanganan yang selama ini sudah dilakukan ternyata berbanding lurus dengan perkembangan kawasan kumuh baru. RKP-KP Kota Surabaya tahun 2016 telah menetapkan Kelurahan Kedung Cowek sebagai salah satu kawasan prioritas pertama penanganan permukiman kumuh di Kota Surabaya [1].

Untuk menindaklanjuti hal tersebut, pemerintah Kota Surabaya terus berupaya dalam mengentaskan kemiskinan dengan pendekatan yang berbasis partisipasi masyarakat (community based development), salah satunya melalui pelaksanaan kegiatan Global Partnership Output Based Aid (GPOBA). Program ini merupakan salah satu program implementasi komunikasi berbasis pembangunan partisipatif yang bertujuan untuk meningkatkan akses air bersih dalam upaya mengurangi jumlah permukiman kumuh di Kota Surabaya. Partisipasi masyarakat merupakan salah satu prasyarat utama penentu keberhasilan program, sehingga langkah yang diambil oleh pemerintah sesuai dengan tujuan bersama [2].

Pada kenyataannya, partisipasi masyarakat di Kelurahan Kedung Cowek dinilai masih kurang maksimal sehingga berpengaruh langsung terhadap kegagalan program. Hal ini disebabkan oleh beberapa faktor yaitu tingkat pendidikan, pengetahuan akan perencanaan pembangunan, dan mata pencaharian masyarakat yang sebagian besar berprofesi sebagai nelayan [3].

Dalam berbagai disiplin ilmu, proses segmentasi beberapa variabel struktur dan perilaku masyarakat telah berhasil dilakukan untuk melihat kecenderungan partisipasi masyarakat. Menurut teori pemasaran yang termuat dalam disiplin ilmu marketing, segmentasi psikografis umumnya dimanfaatkan oleh produsen untuk melihat kecenderungan masyarakat yang berperan sebagai konsumen dalam membeli suatu produk atau jasa [4]. Sejalan dengan konsep tersebut, penelitian terkait segmentasi psikografis masyarakat yang dilakukan di Greater Brisbane, Australia telah membuktikan bahwa kondisi psikografis dapat membantu pemerintah dalam upaya penyampaian maupun perubahan program, serta meningkatkan inisiatif masyarakat dalam peningkatan keberhasilan suatu program. Sangat memungkinkan apabila suatu segmen masyarakat dengan kondisi demografis yang serupa namun memiliki karakteristik psikografis yang berbeda. Oleh karena itu, proses identifikasi karakter psikografis pada suatu segmen sangatlah bermanfaat karena dapat melihat partisipasi masyarakat yang dipengaruhi oleh sikap dan pilihan dalam menanggapi suatu program [5].

Dengan konsep VALS (Value and Lifestyle), kondisi psikografis masyarakat di Kelurahan Kedung Cowek dapat diidentifikasi berdasarkan sikap, kebutuhan, keinginan, keyakinan, dan demografinya [6]. Didasari oleh teori hierarchy of maslow, VALS membagi masyarakat ke dalam kelompok-kelompok tertentu sesuai dengan sifat psikologisnya.

Mengingat tingkat partisipasi masyarakat di Kelurahan Kedung Cowek tergolong rendah, maka perlu dilakukan segmentasi psikografis dengan konsep VALS pada masyarakat setempat, sehingga dapat diketahui penyebab kegagalan program pembangunan yang selama ini sudah berjalan. Hasil identifikasi ini merupakan langkah awal bagi pemerintah Kota Surabaya untuk dapat meningkatkan partisipasi masyarakat dan mempersiapkan program pembangunan di Kelurahan Kedung Cowek yang sesuai dengan kondisi psikografis masyarakat setempat.

\section{METODE PENELITIAN}

\section{A. Pendekatan dan Jenis Penelitian}

Penelitian ini menggunakan pendekatan rasionalistik, yaitu penelitian yang menggunakan akal sebagai patokan dalam menganalisa suatu masalah. Sedangkan jenis penelitian yang 
dilakukan adalah penelitian eksplanatori (explanatory research).

\section{B. Variabel Penelitian}

Penelitian ini menggunakan 8 variabel psikografis berdasarkan konsep VALS, yaitu innovators, thinkers, believers, achievers, strivers, experiencers, makers, dan survivors. Sementara itu, masing-masing variabel psikografis dideskripsikan oleh 3 sifat yang menjadi sub variabel penelitian.

Tabel 1.

Konsep Psikografis Berdasarkan VALS

\begin{tabular}{|c|c|c|}
\hline $\begin{array}{c}\text { Segmen } \\
\text { Psikografis } \\
\end{array}$ & $\begin{array}{c}\text { Ciri-ciri Segmen } \\
\text { Psikografis } \\
\end{array}$ & Keterangan \\
\hline Innovators & $\begin{array}{l}\text { Sophisticated } \\
\text { In Charge } \\
\text { Curious }\end{array}$ & $\begin{array}{l}\text { Berpengalaman /pandai } \\
\text { Suka memimpin } \\
\text { Keingintahuan tinggi }\end{array}$ \\
\hline Thinkers & $\begin{array}{l}\text { Informed } \\
\text { Reflective and } \\
\text { value order } \\
\text { Content }\end{array}$ & $\begin{array}{l}\text { Selalu mendapat informasi } \\
\text { Taat pada aturan } \\
\text { Menyukai pendapat atau opini }\end{array}$ \\
\hline Believers & $\begin{array}{l}\text { Literal } \\
\text { Moralistic } \\
\text { Loyal }\end{array}$ & $\begin{array}{l}\text { Menyukai fakta } \\
\text { Mengikuti ketentuan moral } \\
\text { Setia }\end{array}$ \\
\hline Achievers & $\begin{array}{l}\text { Goal oriented } \\
\text { Brand conscious } \\
\text { Conventional }\end{array}$ & $\begin{array}{l}\text { Bertujuan pada pencapaian } \\
\text { Sadar terhadap merek } \\
\text { Menyukai hal umum / biasa }\end{array}$ \\
\hline Strivers & $\begin{array}{l}\text { Contemporary } \\
\text { Imitative } \\
\text { Style conscious }\end{array}$ & $\begin{array}{l}\text { Masa kini / berjiwa modern } \\
\text { Suka meniru } \\
\text { Sadar terhadap gaya }\end{array}$ \\
\hline Experiencers & $\begin{array}{l}\text { Trend seeking } \\
\text { Impulsive } \\
\text { Variety seeking }\end{array}$ & $\begin{array}{l}\text { Suka mencari hal-hal yang } \\
\text { sedang ramai diperbincangkan } \\
\text { Bertindak tanpa berpikir } \\
\text { Suka mencari keragaman }\end{array}$ \\
\hline Makers & $\begin{array}{l}\text { Responsible } \\
\text { Practical } \\
\text { Self-sufficient }\end{array}$ & $\begin{array}{l}\text { Bertanggung jawab } \\
\text { Suka membuat sesuatu } \\
\text { Mandiri }\end{array}$ \\
\hline Survivors & $\begin{array}{l}\text { Nostalgic } \\
\text { Constrained } \\
\text { Cautious }\end{array}$ & $\begin{array}{l}\text { Menyimpan kenangan masa lalu } \\
\text { Suka memaksakan sesuatu } \\
\text { Waspada / hati-hati }\end{array}$ \\
\hline
\end{tabular}

*Masing-masing variabel psikografis diwakilkan oleh 3 sub-variabel psikografis

\section{Pengumpulan Data}

Sebagian besar data diperoleh melalui survey primer menggunakan kuesioner, sehingga data yang digunakan berasal dari responden atau pihak yang bersangkutan. Terdapat 24 pertanyaan dalam kuesioner yang mewakili 24 sub-variabel penelitian. Akan tetapi dalam penyusunannya, data yang diperoleh oleh peneliti tidak terbatas dari data primer saja, melainkan juga dari data sekunder dalam upaya mengkaji variabel yang digunakan dalam melakukan analisis penelitian.

\section{Teknik Analisis}

Penelitian ini menggunakan teknik analisis kuantitatif melalui metode scoring dengan skala likert (rentang nilai 14). Kuesioner penelitian memuat pertanyaan dengan opsi pilihan jawaban terkait kondisi psikografis masyarakat menurut penilaiannya terhadap diri sendiri. Setelah mengumpulkan data melalui kuesioner, dilakukan penilaian (scoring) terhadap data yang diperoleh untuk memetakan masyarakat ke dalam segmen-segmen sejenis di Kelurahan Kedung Cowek.

Tinggi rendahnya sifat psikografis seseorang pada suatu segmen dapat dilihat melalui nilai total dari 3 butir pertanyaan yang mewakili segmen tersebut. Dengan total pertanyaan sejumlah 24 nomor, maka dapat diidentifikasi 8 segmen psikografis dalam diri seorang responden. Total nilai tertinggi responden pada suatu segmen menyatakan kecenderungan kondisi psikografis orang tersebut.

\section{HASIL DAN PEMBAHASAN}

\section{A. Profil Kawasan Kumuh Kelurahan Kedung Cowek}

Kawasan permukiman kumuh di Kelurahan Kedung Cowek berdasarkan SK Walikota Surabaya berada di RW 1 RT 4 [7], namun kawasan tersebut sudah tidak lagi kumuh sehingga lokasi permukiman kumuh mengalami perubahan yaitu terletak di RW 2 dan 3. Secara administrasi, kawasan permukiman kumuh terletak di Kecamatan Bulak. Luasan kawasan kumuh di Kelurahan Kedung Cowek berdasarkan hasil verifikasi RKP-KP Kota Surabaya seluas 5,01 Ha [1]. Batas fisik kawasan permukiman di Kawasan Kedung Cowek adalah sebagai berikut.

Batas Utara : Selat Madura

Batas Timur : Selat Madura

Batas Selatan : Jalan Cumpat

Batas Barat : Jalan Nambangan Perak

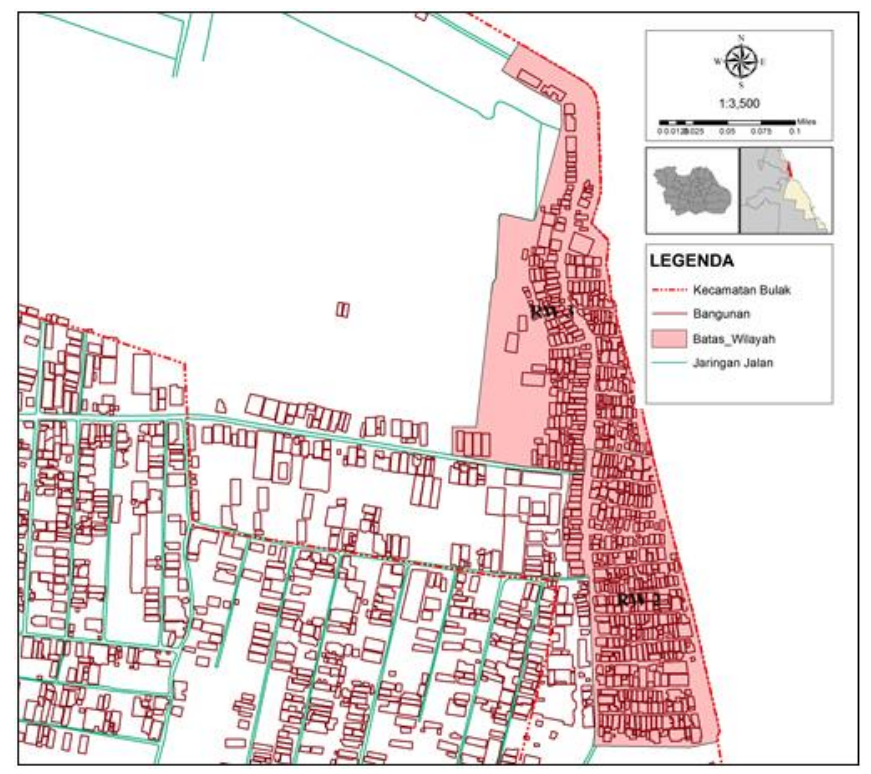

Gambar 1. Kawasan Kumuh Kelurahan Kedung Cowek

Adapun detail kawasan permukiman kumuh Kelurahan Kedung Cowek dapat dilihat pada tabel berikut:

Tabel 2.

Kondisi Fisik Permukiman Kumuh di Kelurahan Kedung Cowek[1]

\begin{tabular}{|c|c|c|}
\hline $\begin{array}{l}\text { Kriteria } \\
\text { Kumuh }\end{array}$ & Indikator & Parameter \\
\hline \multirow{5}{*}{$\begin{array}{l}\text { Kondisi } \\
\text { Fisik }\end{array}$} & $\begin{array}{l}\text { Keteraturan } \\
\text { Bangunan }\end{array}$ & $\begin{array}{l}184 \text { Unit bangunan hunian tidak memiliki } \\
\text { keteraturan. }\end{array}$ \\
\hline & $\begin{array}{l}\text { Kepadatan } \\
\text { Bangunan }\end{array}$ & $\begin{array}{l}\text { Kawasan permukiman memiliki Kepadatan } \\
109 \text { Unit/ Ha. }\end{array}$ \\
\hline & $\begin{array}{l}\text { Kelayakan } \\
\text { Fisik } \\
\text { Bangunan }\end{array}$ & $\begin{array}{l}\text { - } 148 \text { Unit bangunan hunian memiliki } \\
\text { Luas Lantai }<7,2 \mathrm{~m}^{2} \text { per orang. } \\
\text { - } 127 \text { Unit bangunan memiliki kondisi } \\
\text { Atap, Lantai, Dinding tidak sesuai } \\
\text { persyaratan teknis. }\end{array}$ \\
\hline & $\begin{array}{l}\text { Aksesibilitas } \\
\text { Lingkungan }\end{array}$ & $\begin{array}{l}\text { - } 2.600 \text { Meter kawasan permukiman tidak } \\
\text { terlayani jaringan jalan lingkungan yang } \\
\text { memadai. } \\
\text { - } 3.300 \text { Meter kondisi jaringan jalan pada } \\
\text { kawasan permukiman memiliki kualitas } \\
\text { buruk. }\end{array}$ \\
\hline & $\begin{array}{l}\text { Drainase } \\
\text { Lingkungan }\end{array}$ & $\begin{array}{l}\text { - 2,65 Ha Kawasan permukiman terjadi } \\
\text { genangan/banjir. }\end{array}$ \\
\hline
\end{tabular}




\begin{tabular}{|c|c|}
\hline & $\begin{array}{l}\text { - } 700 \text { Meter kondisi jaringan drainse pada } \\
\text { lokasi permukiman memiliki kualitas } \\
\text { buruk. }\end{array}$ \\
\hline $\begin{array}{l}\text { Pelayanan } \\
\text { Air } \\
\text { Minum/Baku }\end{array}$ & $\begin{array}{l}\text { - } 20 \text { Unit bangunan hunian pada lokasi } \\
\text { permukiman tidak terlayani jaringan Air } \\
\text { Bersih/Baku perpipaan atau non } \\
\text { perpipaan terlindungi yang layak. } \\
\text { - Unit Rumah Tangga tidak terpenuhi } \\
\text { kebutuhan minimal 60liter/org/hari } \\
\text { (Mandi, Minum, Cuci). }\end{array}$ \\
\hline & $\begin{array}{l}\text { - } 87 \text { Unit bangunan hunian pada lokasi } \\
\text { permukiman tidak memiliki akses } \\
\text { Jamban/MCK Komunal. } \\
\text { - } 84 \text { Unit bangunan hunian pada lokasi } \\
\text { permukiman tidak memiliki kloset } \\
\text { (Leher Angsa) yang terhubung dengan } \\
\text { tangkiseptik. } \\
\text { - Keseluruhan saluran pembuangan Air } \\
\text { Limbah Rumah Tangga tercampur } \\
\text { dengan drainase lingkungan. }\end{array}$ \\
\hline $\begin{array}{l}\text { Penge } \\
\text { Persa }\end{array}$ & $\begin{array}{l}485 \text { Unit sampah domestik rumah tangga } \\
\text { pada kawasan permukiman terangkut ke } \\
\text { TPS/TPA kurang dari } 2 \text { kali seminggu }\end{array}$ \\
\hline $\begin{array}{l}\text { Pengamanan } \\
\text { Bahaya } \\
\text { Kebakaran }\end{array}$ & $\begin{array}{l}3,01 \text { Ha Kawasan permukiman tidak } \\
\text { memiliki Ketersediaan prasarana/sarana } \\
\text { Proteksi Kebakaran }\end{array}$ \\
\hline $\begin{array}{l}\text { Legalitas } \\
\text { pendirian } \\
\text { bangunan }\end{array}$ & $\begin{array}{l}293 \text { Unit bangunan hunian tidak memiliki } \\
\text { IMB. } \\
58 \text { Unit lahan bangunan hunian tidak } \\
\text { memiliki SHM/HGB/Surat yang diakui } \\
\text { pemerintah. }\end{array}$ \\
\hline
\end{tabular}
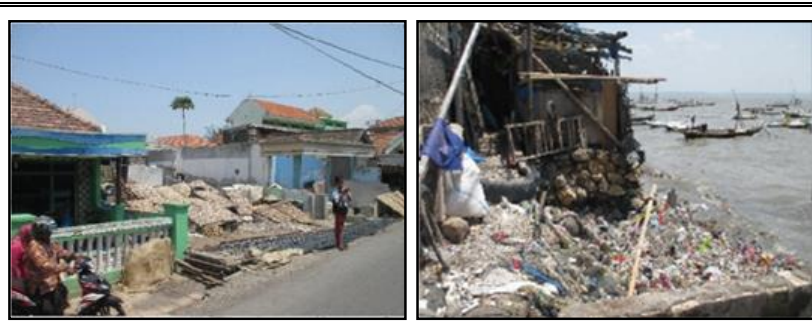

Gambar 2. Kondisi Fisik Bangunan dan Pengelolaan Persampahan di RW 2 Kelurahan Kedung Cowek
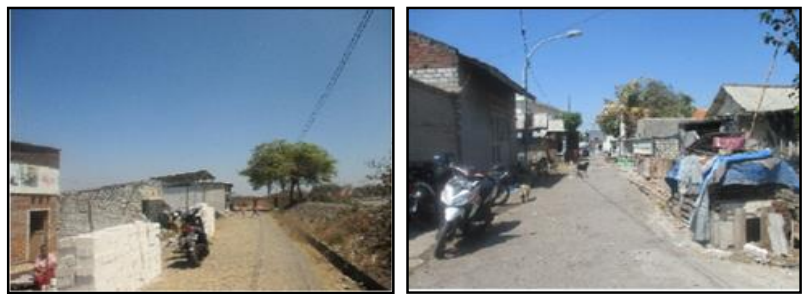

Gambar 3. Kondisi Aksesibilitas Lingkungan dan Drainase di RW 3 Kelurahan Kedung Cowek

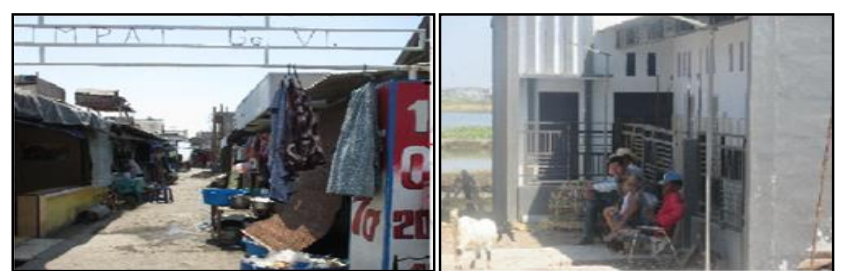

Gambar 4. Kondisi Kepadatan dan Kelayakan Bangunan di Kelurahan Kedung Cowek

Tabel 3 .

Kondisi Non-Fisik Permukiman Kumuh di Kelurahan Kedung Cowek

\begin{tabular}{|c|c|c|}
\hline $\begin{array}{l}\text { Kriteria } \\
\text { Kumuh }\end{array}$ & Indikator & Parameter \\
\hline \multirow{5}{*}{$\begin{array}{l}\text { Kondisi } \\
\text { Non-Fisik }\end{array}$} & $\begin{array}{l}\text { Kepadat } \\
\text { an } \\
\text { penduduk }\end{array}$ & Kepadatan Penduduk 345 Jiwa/Ha \\
\hline & $\begin{array}{c}\text { Mata } \\
\text { pencarian } \\
\text { penduduk }\end{array}$ & $\begin{array}{l}\text { Mata pencaharian utama rumah tangga } \\
\text { adalah perdagangan jasa }\end{array}$ \\
\hline & $\begin{array}{l}\text { Penggun } \\
\text { aan Daya } \\
\text { Listrik }\end{array}$ & $\begin{array}{l}\text { Mayoritas rumah tangga menggunakan } \\
\text { daya listrik } 900 \text { Watt }\end{array}$ \\
\hline & $\begin{array}{l}\text { Fasilitas } \\
\text { Pelayanan } \\
\text { Kesehatan } \\
\end{array}$ & $\begin{array}{crr}\text { Mayoritas } & \begin{array}{r}\text { Rumah tangga } \\
\text { menggunakan }\end{array} & \text { dikawasan } \\
\text { permukiman } & \text { failitas } \\
\text { kesehatan di Puskesmas } & \\
\end{array}$ \\
\hline & $\begin{array}{l}\text { Fasilitas } \\
\text { Pelayanan } \\
\text { Pendidikan }\end{array}$ & $\begin{array}{l}\text { Mayoritas Rumah tangga memiliki usia } \\
\text { wajib belajar 9 Tahun (SD-SMP) } \\
\text { memperoleh akses pendidikan dasar di } \\
\text { dalam Kelurahan/ Kecamatan yang sama. }\end{array}$ \\
\hline
\end{tabular}

Sumber : RKP-KP Kota Surabaya, 2015

Berdasarkan profil permukiman kumuh RKP-KP Kota Surabaya (2015), kondisi eksisting Kawasan Kumuh Kelurahan Kedung Cowek adalah sebagai berikut:

1. Kondisi fisik bangunan mayoritas permanen;

2. Kepadatan bangunan sedang;

3. KDB eksisting berkisar antara $90 \%-100 \%$;

4. Kondisi permukaan jalan berpaving dan kondisinya buruk;

5. Saluran air hujan dalam kondisi buruk dan dangkal;

6. Pelayan pipa air minum (SR) hampir $99 \%$ terlayani air bersih PDAM;

7. Hampir keseluruhan rumah sudah memiliki jamban yang dilengkapi septitank;

8. Tidak terdapat bak sampah di tiap-tiap rumah;

9. Belum memiliki sarana proteksi terhadap bahaya kebakaran.

\section{B. Identifikasi Segmen Masyarakat di Kelurahan Kedung Cowek Berdasarkan Variabel Psikografis}

RW 2 dan RW 3 Kelurahan Kedung Cowek merupakan salah satu kawasan kumuh dengan prioritas penanganan pertama di Surabaya. Seluruh masyarakat yang berada pada RW 2 dan RW 3 dianggap setara karena memiliki kondisi demografis yang serupa. Oleh karena itu, berdasarkan hasil penelitian kepada 87 sampel yang terpilih secara acak dengan rumus slovin, diketahui bahwa kondisi psikografis masyarakat di Kelurahan Kedung Cowek pada 8 segmen psikografis menurut konsep VALS adalah sebagai berikut:

Tabel 4.

Kondisi Psikografis Masyarakat di Kelurahan Kedung Cowek

\begin{tabular}{cc}
\hline \hline Segmen & Jumlah \\
Psikografis & \\
\hline Innovators & 10 \\
Thinkers & 20 \\
Believers & 22 \\
Achievers & 4 \\
Strivers & 7 \\
Experiencers & 9 \\
Makers & 2 \\
Survivors & 13 \\
\hline
\end{tabular}

Berikut merupakan diagram persentase kondisi psikografis masyarakat di Kelurahan Kedung Cowek. 


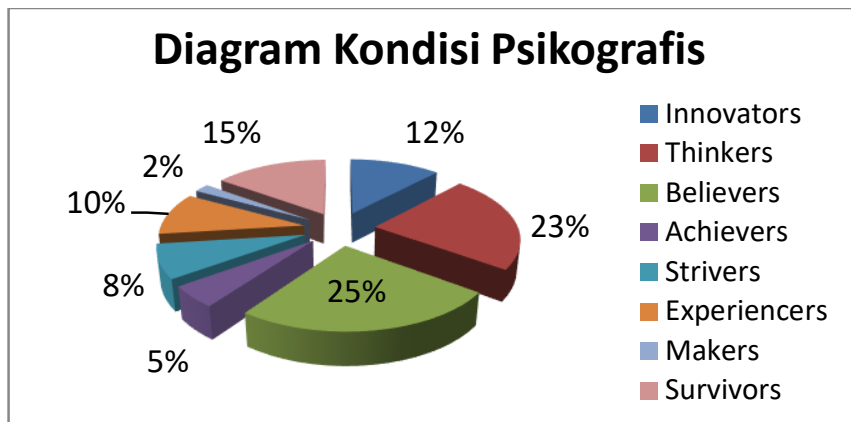

Gambar 5. Diagram Kondisi Psikografis Masyarakat di Kelurahan Kedung Cowek

Data tersebut menunjukkan bahwa masyarakat di Kelurahan Kedung Cowek memiliki kondisi psikografis yang berbeda-beda. Sifat yang paling banyak ditemukan adalah Believers, yaitu sekumpulan orang yang konservatif, konvensional dalam memegang keyakinan dan kepercayaan atas dasar kode-kode tradisional dan sudah didirikan, sehingga lamban untuk menghadapi perubahan dan sulit menerima teknologi. Sifat dominan berikutnya adalah Thinkers. Masyarakat yang memiliki sifat ini umumnya senang mencari informasi dan mengolahnya. Mereka taat pada aturan dan kepercayaan yang diyakini, serta suka mendengarkan dan memberikan pendapat atau opini untuk menambah wawasan dan pengetahuannya. Masyarakat dengan sifat Thinkers umumnya terbuka pada perubahan. Sementara itu, sifat yang paling sedikit ditemukan adalah Makers, yaitu kumpulan orang yang fokus terhadap hal-hal yang sudah dikenal, seperti keluarga, pekerjaan dan kesenangan fisik (konstruktif dengan tangan), praktis yang memiliki kemampuan membangun dan menghargai kemandirian diri serta memiliki minat rendah terhadap dunia luas.

Adapun dominasi kondisi psikografis masyarakat pada masing-masing RT dan RW di Kelurahan Kedung Cowek berbeda-beda. Pada saat pengambilan sampel penelitian yang berjumlah 87 orang, 44 responden bertempat tinggal di RW 2 , sementara itu 43 responden lainnya bertempat tinggal di RW3. Berdasarkan jumlah tersebut, total responden pada masing-masing RW dibagi rata sesuai dengan jumlah RT yang ada pada RW yang bersangkutan. Masing-masing RW memiliki 3 RT yang termasuk dalam kawasan kumuh, sehingga terdapat 14-15 responden yang menjadi sampel pada masing-masing RT di Kelurahan Kedung Cowek. Berikut ini merupakan sebaran kondisi psikografis masyarakat pada RW 2 (Jalan Cumpat) dan RW 3 (Jalan Nambangan).

Tabel 5.

Sebaran Kondisi Psikografis di Kelurahan Kedung Cowek

\begin{tabular}{|c|c|c|c|c|c|c|}
\hline \multirow{2}{*}{$\begin{array}{c}\text { Segmen } \\
\text { Psikografis }\end{array}$} & \multicolumn{3}{|c|}{ RW 2} & \multicolumn{3}{|c|}{ RW 3} \\
\hline & $\begin{array}{l}\mathrm{R} \\
\mathrm{T} 1\end{array}$ & $\begin{array}{l}\mathrm{R} \\
\mathrm{T} 2\end{array}$ & $\begin{array}{l}\mathrm{R} \\
\mathrm{T} 3\end{array}$ & $\begin{array}{l}\mathrm{R} \\
\mathrm{T} 1\end{array}$ & $\begin{array}{l}\mathrm{RT} \\
2\end{array}$ & $\begin{array}{l}\mathrm{RT} \\
3\end{array}$ \\
\hline Innovators & 1 & 4 & 0 & $4^{*}$ & 1 & 0 \\
\hline Thinkers & ${ }_{*}^{5}$ & 2 & 1 & 3 & $6^{*}$ & 3 \\
\hline Believers & 2 & $5^{*}$ & 3 & 1 & 2 & $9 *$ \\
\hline Achievers & 2 & 0 & 1 & 0 & 1 & 0 \\
\hline Strivers & 0 & 0 & $5^{*}$ & 0 & 1 & 1 \\
\hline $\begin{array}{l}\text { Experience } \\
\text { rs }\end{array}$ & 1 & 1 & 3 & 1 & 1 & 2 \\
\hline Makers & 0 & 0 & 0 & 2 & 0 & 0 \\
\hline Survivors & 3 & 3 & 2 & 3 & 2 & 0 \\
\hline
\end{tabular}

Secara spasial, berikut merupakan sebaran kondisi psikografis masyarakat pada masing-masing RT di Kelurahan Kedung Cowek.

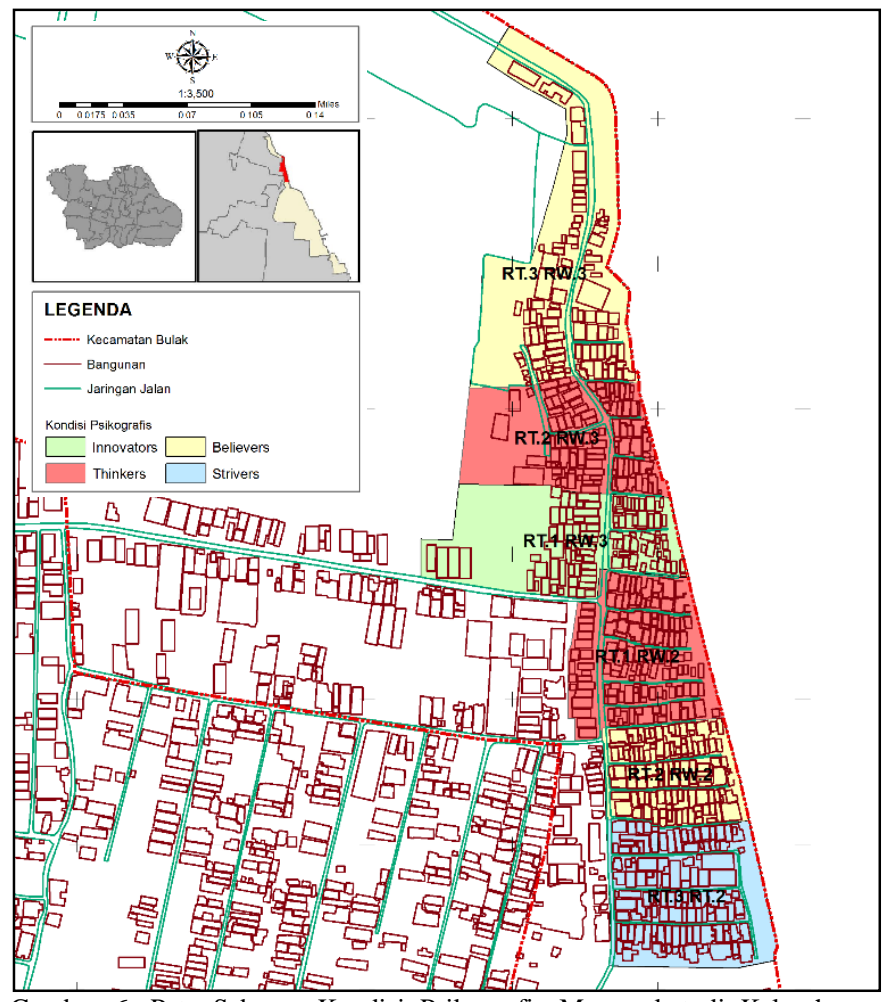

Gambar 6. Peta Sebaran Kondisi Psikografis Masyarakat di Kelurahan Kedung Cowek

Melalui gambar tersebut, terlihat bahwa kecenderungan kondisi psikografis masyarakat di Kelurahan Kedung Cowek pada masing-masing wilayah beragam. Terdapat 4 kondisi psikografis yang dominan pada masing-masing RT, yaitu believers, thinkers, innovators, dan strivers.

\section{Identifikasi Segmen Psikografis Ketua KSM di Kelurahan Kedung Cowek}

Kedung Cowek memiliki 16 Kelompok Swadaya Masyarakat yang berperan dalam Program Penataan Lingkungan Permukiman Berbasis Komunitas (PLP-BK). Pada program tersebut, masing-masing KSM memiliki lingkup pekerjaan yang berbeda-beda. Sementara itu, partisipasi masyarakat di Kelurahan Kedung Cowek masih tergolong rendah [3]. Oleh karena itu, dibutuhkan identifikasi kondisi psikografis berdasarkan konsep VALS terhadap masing-masing ketua KSM. Hal ini ditujukan sebagai langkah awal untuk melihat kondisi psikografis para penggerak masyarakat di Kelurahan Kedung Cowek. Nantinya hasil penelitian ini dapat dikaitkan dengan tingkat partisipasi para penggerak KSM dalam program PLP-BK, sehingga pola hubungan antara kondisi psikografis dengan partisipasi seseorang dapat terlihat.

Adapun hasil identifikasi kondisi psikografis 16 Ketua KSM berdasarkan konsep VALS dapat dilihat pada Tabel 3. 
Tabel 6.

Kondisi Psikografis Ketua KSM di Kelurahan Kedung Cowek

\begin{tabular}{lc}
\hline \hline Nama KSM & Kondisi Psikografis \\
\hline Kerang Bambu 1 & Experiencers \\
Kerang Bambu 2 & Believers \\
Kerang Bambu 3 & Strivers \\
Kerang Sempeng & Experiencers \\
Kerang Wadung & Thinkers \\
Kerang Tutuk 1 & Innovators \\
Kerang Tutuk 2 & Innovators \\
Kerang Kupang & Survivors \\
Kepiting 1 & Innovators \\
Kepiting 2 & Innovators \\
Kepiting 3 & Innovators \\
Baronang 1 & Thinkers \\
Baronang 2 & Thinkers \\
Baronang 3 & Makers \\
Kakap & Thinkers \\
Cumi-Cumi & Makers \\
\hline
\end{tabular}

Berdasarkan tabel tersebut, diketahui bahwa kondisi psikografis 16 ketua KSM di Kelurahan Kedung Cowek adalah beragam. Sifat yang paling dominan adalah innovators dan thinkers. Kedua sifat ini memiliki beberapa kemiripan, yaitu memiliki pengetahuan yang luas, terbuka atas hal-hal baru, dan memiliki jiwa kepemimpinan tinggi. Dengan kata lain, seseorang dengan sifat innovators dan thinkers secara teoritis memang layak untuk menjadi pemimpin dalam masyarakat. Akan tetapi, masyarakat dengan kondisi psikografis thinkers juga membutuhkan ruang untuk mengolah informasi yang diterimanya, sehingga seorang thinkers tidak mampu membuat keputusan yang cepat dan tepat dalam keadaan terdesak jika dibutuhkan pada saat memimpin masyarakat.

\section{KESIMPULAN}

Kesimpulan dari proses identifikasi segmen masyarakat di Kelurahan Kedung Cowek adalah sebagai berikut:

1) Masyarakat setempat memiliki kondisi psikografis yang berbeda-beda.

- Sifat psikografis yang paling banyak dimiliki oleh masyarakat di Kelurahan Kedung Cowek adalah believers, yaitu seseorang yang konservatif, konvensional dan memegang teguh keyakinan serta kepercayaan atas dasar kode - kode tradisional yang sudah didirikan, lamban untuk berubah dan sulit mengikuti perubahan teknologi.

- Sifat dominan selanjutnya adalah thinkers, yaitu seseorang yang menghargai perintah, pengetahuan, serta tanggung jawab. Sebagian besar kelompok masyarakat dengan gaya hidup thinkers memperoleh informasi terkait program PLPBK dengan baik, dan selalu terbuka akan ide baru serta perubahan sosial.

- Sifat psikografis yang paling jarang ditemukan adalah makers, yaitu sekumpulan orang yang bertanggung jawab, mandiri dan sangat menghargai nilai dari suatu produk dibandingkan merk dan harga dari produk itu sendiri. Masyarakat di Kelurahan Kedung Cowek dengan sifat psikografis makers umumnya senang membuat barang sendiri dan sedang/pernah memiliki usaha mandiri.
2) Secara spasial, terdapat 4 kondisi psikografis yang mendominasi masing-masing RT di Kelurahan Kedung Cowek, yaitu believers, thinkers, innovators, dan strivers.

3) Kondisi psikografis 16 Ketua KSM yang ada di Kelurahan Kedung Cowek cukup beragam. Sifat yang dominan adalah innovators dan thinkers.

\section{REKOMENDASI}

Adapun rekomendasi yang dapat diberikan berdasarkan penelitian yang telah dilakukan adalah sebagai berikut:

1) Melakukan penelitian lanjutan dengan pokok bahasan sebagai berikut:

- Menilai tingkat partisipasi masyarakat di Kelurahan Kedung Cowek pada program PLP-BK;

- Identifikasi pola hubungan antara kondisi psikografis masyarakat dengan tingkat partisipasi masyarakat di Kelurahan Kedung Cowek;

- Melakukan penelitian serupa di lokasi permukiman kumuh lain.

2) Menjadikan hasil dari penelitian ini sebagai masukan dalam pengadaan program peningkatan kualitas permukiman kumuh di Kelurahan Kedung Cowek agar disesuaikan dengan dominasi kondisi psikografis masyarakat setempat, yaitu believers dan thinkers.

\section{DAFTAR PUSTAKA}

[1] Kementerian PU\&PR Direktorat Jenderal Cipta Karya. (2016). Penyusunan Review Rencana Kawasan Permukiman Kumuh Perkotaan (RKP-KP) Kota Surabaya. Surabaya: Kementerian PU\&PR Direktorat Jenderal Cipta Karya..

[2] Astuti, S. B., \& Cakradiharja, M. (2016). Peranan Partisipasi Masyarakat dalam Perencanaan Pembangunan Desa. Warta Bappeda Provinsi Jawa Barat, Volume 33 No. 4.H. Poor, An Introduction to Signal Detection and Estimation. New York: Springer-Verlag (1985) Ch. 4.

[3] Lailiyah, F. (2016). Implementasi Komunikasi Pembangunan Partisipatif Pada Program GLOBAL PARTNERSHIP OUTPUTBASED AID (GP-OBA) di Kota Surabaya. Thesis.

[4] Susanto, A. S. (2013). Membuat Segmentasi Berdasarkan Life Style (Gaya Hidup). Jurnal JIBEKA, Volume 7, No.2, 1-6.

[5] Muriuki, G., Dowd, A.-M., \& Ashworth, P. (2016). Urban sustainability - a segmentation study of Greater Brisbane, Australia.

[6] Strategic Business Insight. (2017). Strategic Business Insight. Retrieved November 22, 2017, from VALS: http://www.strategicbusinessinsights.com/

[7] SK Walikota Surabaya No. 62/2006 